\title{
Effect of Sitagliptin and Vitamin D3 on Secretion of IL-6 and TNF- $\alpha$ Inflammatory Factors in Patients with Type 2 Diabetes
}

\section{Elham Mahabadi-Ashtiyani ${ }^{1}$, Vida Sheikh², Shiva Borzouei $^{2}$, Iraj Salehi ${ }^{3}$, Mahdi Alahgholi-Hajibehzad ${ }^{4, *}$}

${ }^{1}$ MSc Student of Immunology, School of Medicine, Hamadan University of Medical Sciences, Hamadan, Iran

${ }^{2}$ Assistant Professor, Department of Internal Medicine, School of Medicine, Hamadan University of Medical Sciences, Hamadan, Iran

${ }^{3}$ Professor of Physiology, Neurophysiology Research Center, Hamadan University of Medical Sciences, Hamadan, Iran

${ }^{4}$ Assistant Professor, Department of Immunology, School of Medicine, Hamadan University of Medical Sciences, Hamadan, Iran

* Corresponding Author: Mahdi Alahgholi-Hajibehzad, Department of Immunology, School of Medicine, Hamadan University of Medical Sciences, Hamadan, Iran.Email: mhajibehzad@yahoo.com

Received: 14.07 .2018

Accepted: 10.11 .2018

\section{How to Cite this Article:} Mahabadi-Ashtiyani E, Sheikh V, Borzouei S, Salehi I, Alahgholi-Hajibehzad M. Effect of Sitagliptin and Vitamin D3 on the Secretion of IL-6 and TNF- $\alpha$ Inflammatory Factors in Patients with Type 2 Diabetes. Avicenna J Clin Med. 2018; 25(3): 134-141. DOI: 10.21859/ ajcm.25.3.134

\section{Abstract}

Background and Objective: Diabetes mellitus is one of the most commonly reported diseases that is associated with insulin resistance and increased blood glucose levels. The aim of this study was to determine the probable anti-inflammatory effects of sitagliptin and vitamin D3 (VitD3) on proinflammatory IL-6 and TNF- $\alpha$ in patients with type 2 diabetes mellitus (T2DM).

Materials and Methods: In this case-control study, 20 blood samples of patients with T2DM and healthy controls (HCs) were collected $(\mathrm{n}=20)$. Peripheral blood mononuclear cells (PBMCs) were isolated using the Ficoll-Paque method and cultured with Phytohemagglutinin (PHA) in the presence or absence of sitagliptin and VitD3 for 4 days. The enzymelinked immunosorbent assay was used to analyze the levels of IL-6 and TNF- $\alpha$ produced by PBMCs.

Results: After PHA stimulation, the production of IL-6 was increased significantly in T2DM patients compared to HCs $(\mathrm{P}=0.03)$. Compared to PHA cultures, sitagliptin and VitD3 resulted in the reduction of IL-6 production in patients $(\mathrm{P} \leq 0.001, \mathrm{P} \leq 0.001)$, and $\mathrm{HCs}(\mathrm{P}=0.03, \mathrm{P}=0.02)$, respectively. Moreover, with regard to the cultures with sitagliptin or VitD3, sitagliptin with VitD3 reduced the level of IL-6 in both groups of patients $(\mathrm{P}=0.02, \mathrm{P}=0.002)$ and HCs $(\mathrm{P}=0.002, \mathrm{P}=0.03)$. There was a significant reduction in the level of TNF- $\alpha$ by sitagliptin with VitD3 in patients $(\mathrm{P}=0.04$, $\mathrm{P}=0.002)$ and $\mathrm{HCs}(\mathrm{P}=0.04, \mathrm{P}=0.03)$, compared to cultures with sitagliptin or VitD3.

Conclusion: According to the results, it can be concluded that the combined use of sitagliptin and VitD3 is more influential regarding the antiinflammatory effects on patients. In addition, the reduction of sitagliptin dose may result in decreasing its possible side effects.

Keywords: Diabetes Mellitus Type 2, Sitagliptin, Vitamin D3 


\section{اثر سيتاكليتين و ويتامين D3 بر ترشح فاكتور هاى التهابى TNF-}

\section{مبتلا به ديابت نوع دو}

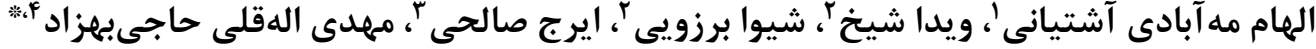

دانشجوى كارشناسى ارشد ايمونولوزى، دانشكده يزشكى، دانشعاه علوم يزشكى همدان، همدان، ايران

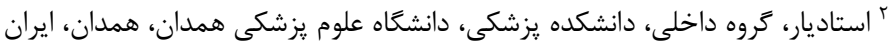

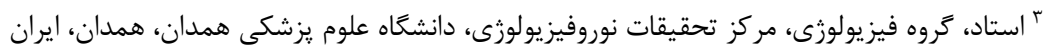

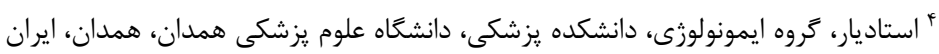

* نويسنده مسئول: مهدى الدقلى حاجىبهزاد، گروه ايمونولورى، دانشكده يزشكى، دانشكاه علوم يزشكى همدان، همدان، ايران. ايميل: mhajibehzad@yahoo.com

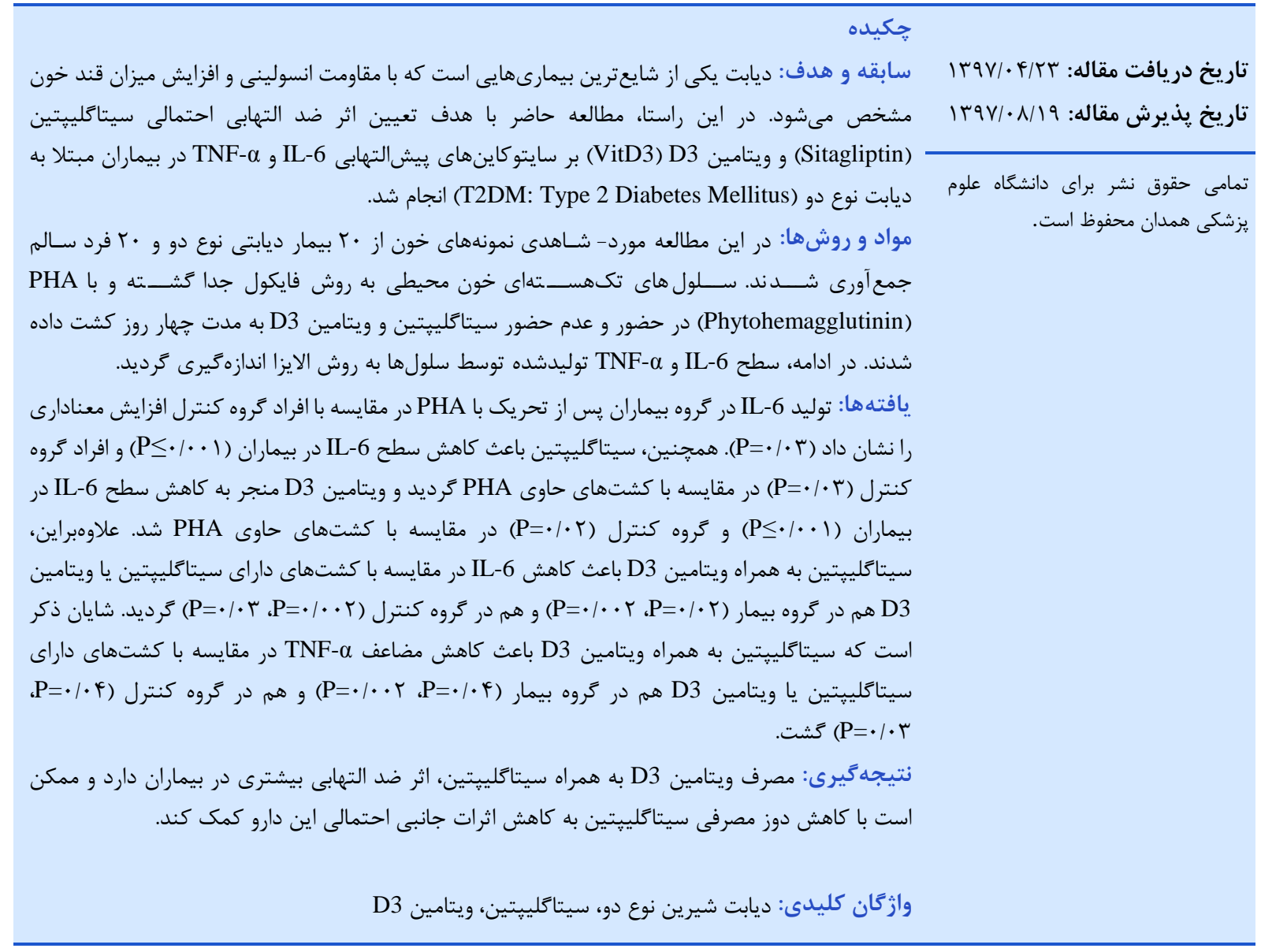

مقلمه4

متفورمين و دسته سولفونيل اورهها نظير كليكلازيد آغاز

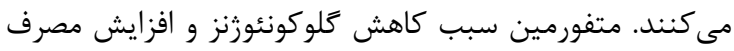
محيطى كلوكز شده و كليكلازيد باعث تحريك و مو آزادشدن سئن

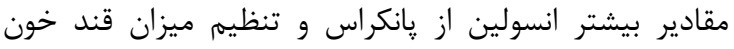

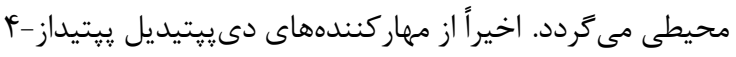
مانند سيتاكلييتين (DPP-4: Dipeptidyl Peptidase-4)
ديابت نوع دو (T2DM) يكى از شايعترين بيمارىهايى

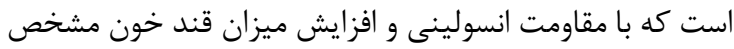

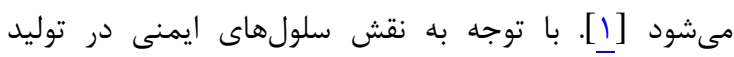

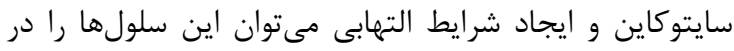

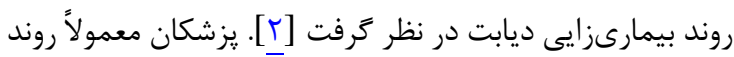

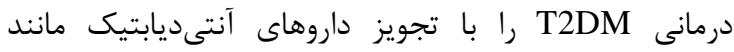


توليد سلولهاى Th17 و مهار سلولهاى T تنظيمى توليدكننده

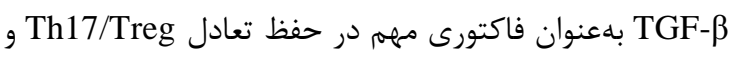

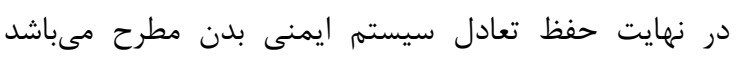

مطالعات مختلف نشان دادهاند كه سطح سرمى سايتوكاينهاى

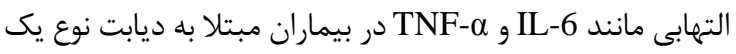

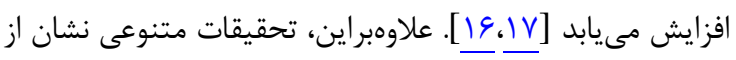

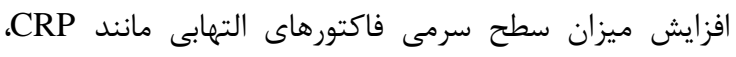
IFN- $\gamma$

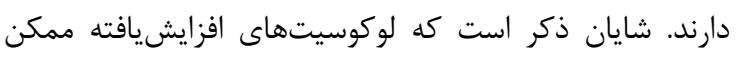

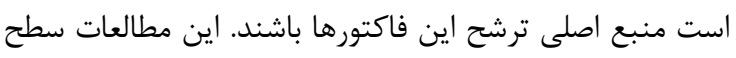

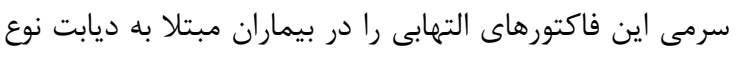

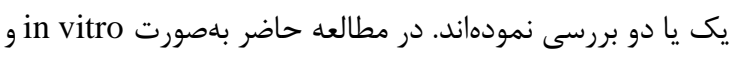

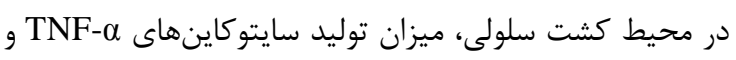

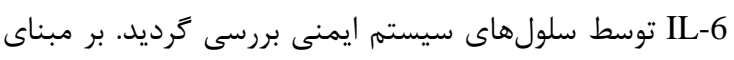

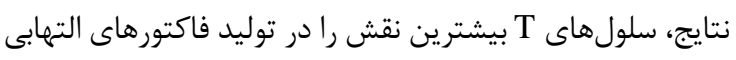

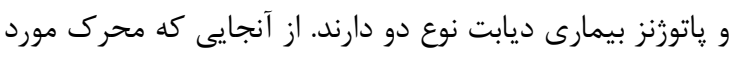

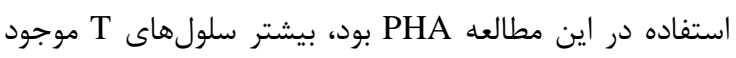

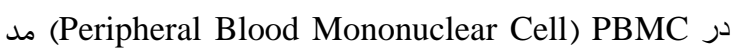
نظر قرار كرفتند. اطلاعات بسيار كمى در ارتباط با تأثير داروى

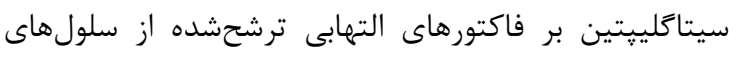

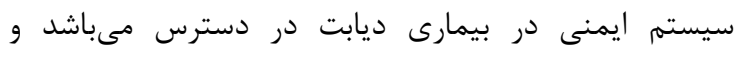

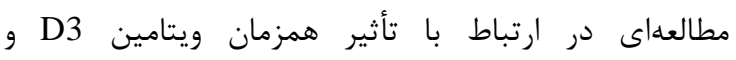

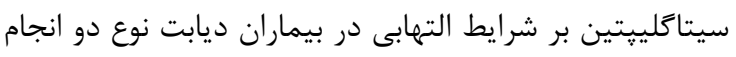

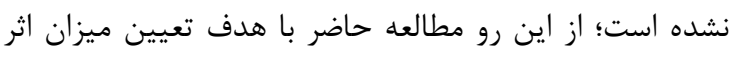

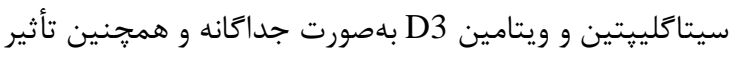

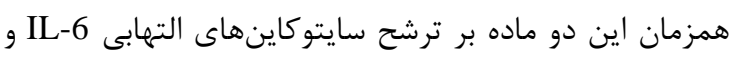
TNF- $\alpha$ نوع دو و كروه كنترل انجام شد.

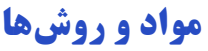 جامعه و ونمونه ئزوهش}

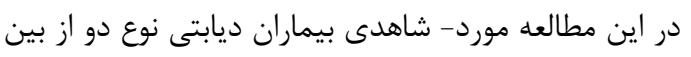

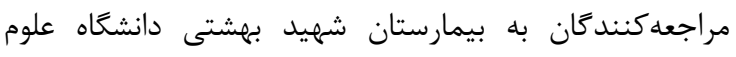

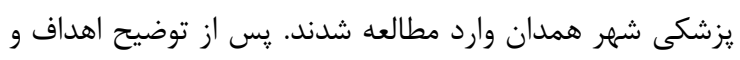

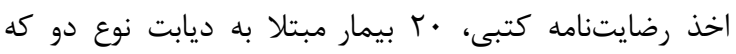

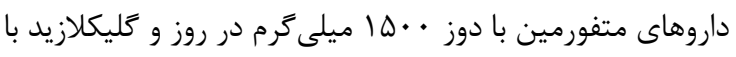

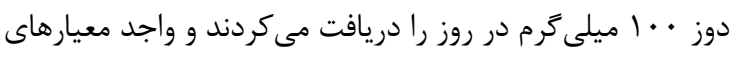

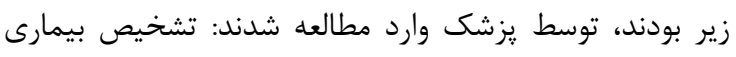

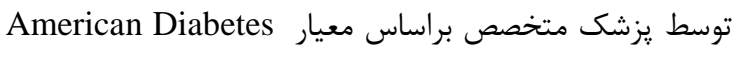
Association

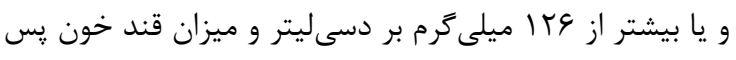

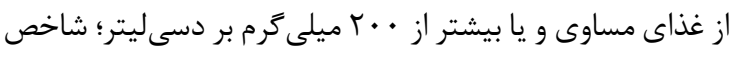

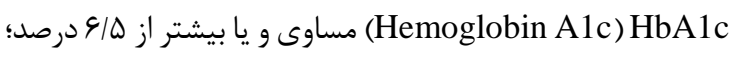

بلعنوان عوامل ضد ديابتيك با اثرات محافظتى بر كليه در درمان

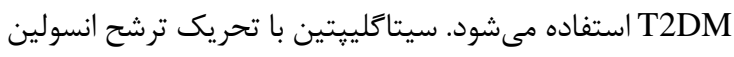

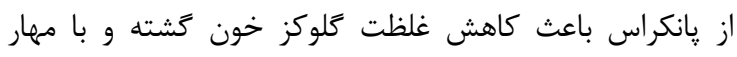

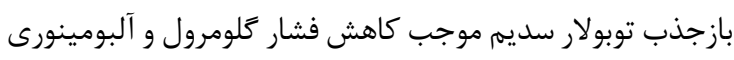

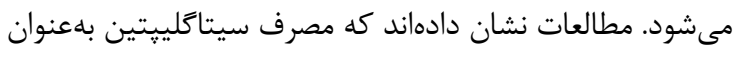

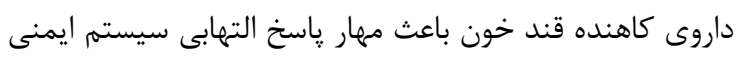

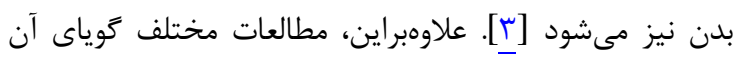

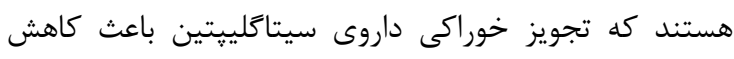

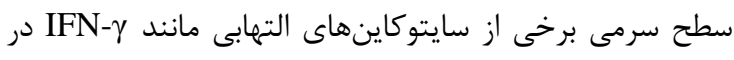

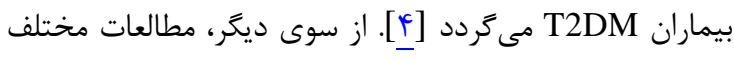

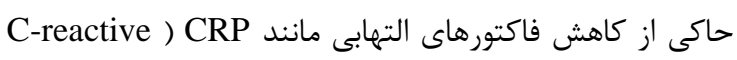

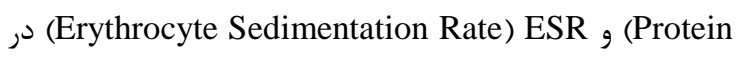
اثر مصرف داروى سيتاكلييتين در بيماران T2DM مى أشباشند

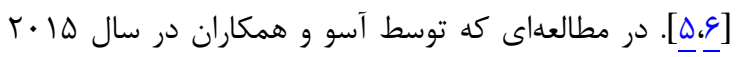

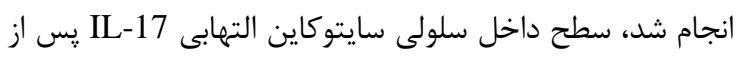

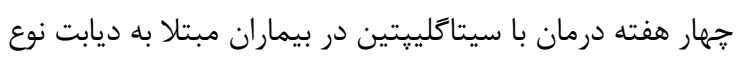

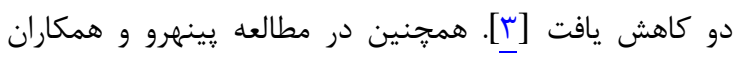

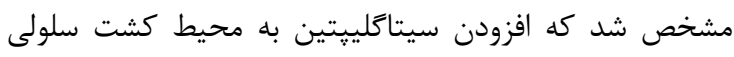
باعث كاهش سطح IFN- و و IL-17 توليدشده از سلولهاى

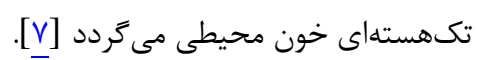

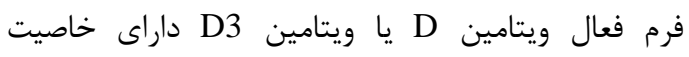

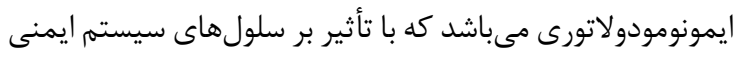

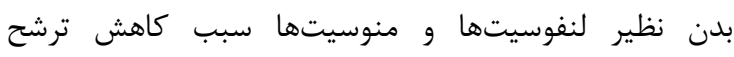

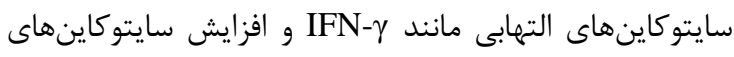

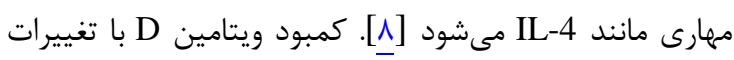

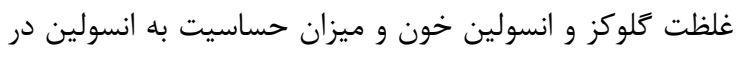

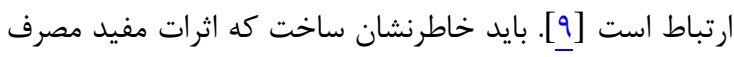

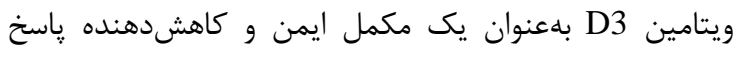

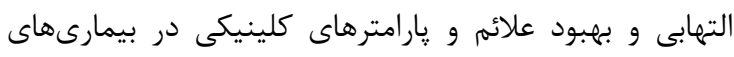

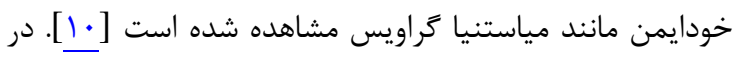

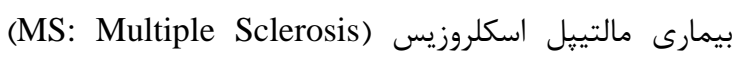

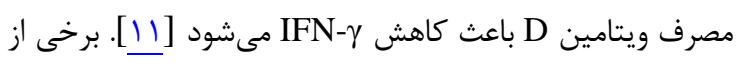

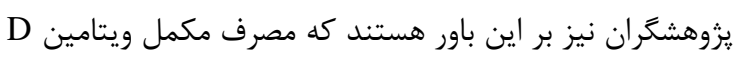

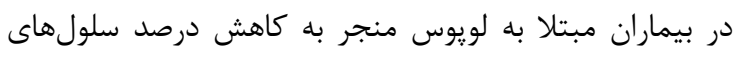

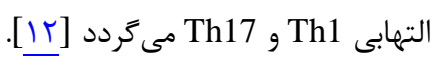

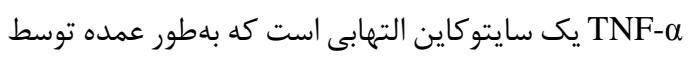
لنفوسيتهاى T و ماكروفازها توليد مى شود و موجب ايتي ايجاد

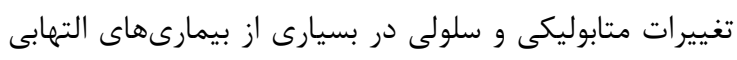

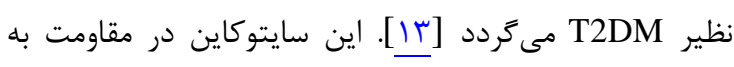

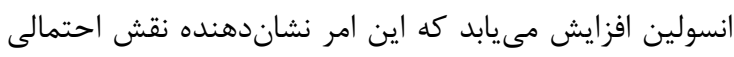

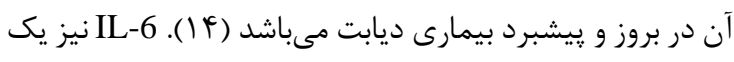

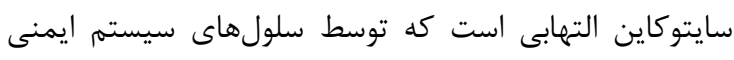

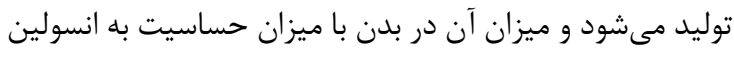

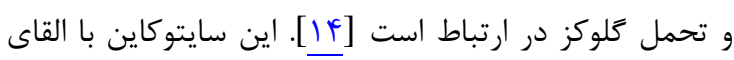




$$
\text { تحريكى وكشت سلول ها }
$$

سلولهاى تكهستهاى خون محيطى (تعداد ه • (Y س سلول)

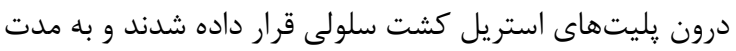
جهار روز با محرى PHA (ه ميكروكرم بر ميلى ليتر)، ويتامين

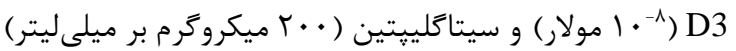
تحريك گرديدند. ذكر اين نكته ضرورت دارد كه دوز مواد مورد

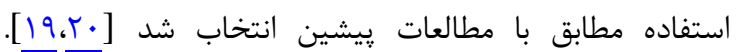

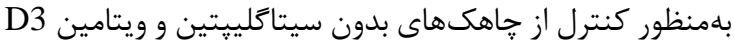

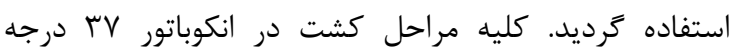

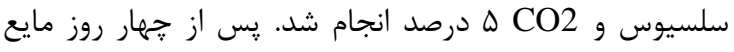

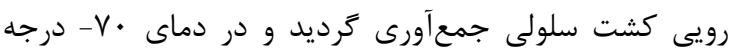

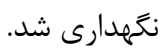

\section{اند/زمكيرى فاكتورهاى التهابى}

سطح فاكتورهاى التهابى IL-6 و TNFسلولهاى كشتدادهشده توسط كيت الايزا (Biolegend، (USA)

$$
\text { و براساس دستور العمل كيت سازنده اندازهخيرى شد. }
$$

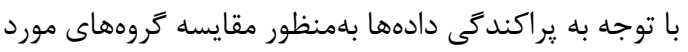

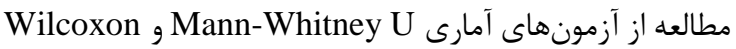

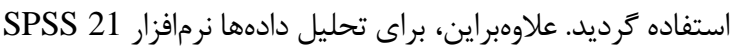
و جهت رسم نمودارها نرمافزار 6.07 Graph Pad Prism مورد تردي

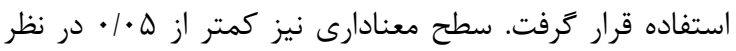
كرفته شد.

\section{يافته ها}

ويزگگىهاى كلينيكى و دموكر افيك افراد مورد مطالعه در جدول

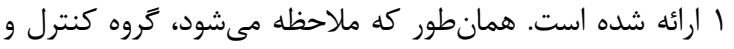
بيمار به لحاظ سن، جنس، طول دوره بيمارى، ميزان كراتينين
نداشتن بيمارى خودايمن، نئويلازى خونى و بافتى و پانكراتيت؛ عدم مصرف استروئيد، انسولين و داروهاى مهاركننده سيستم

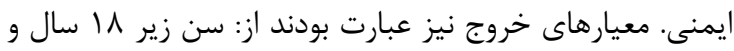

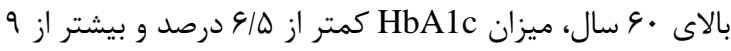

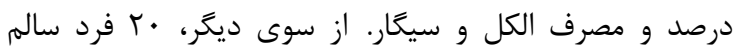

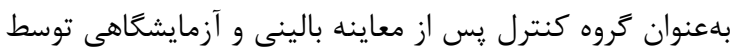

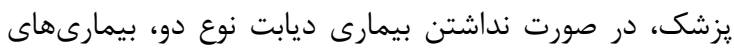

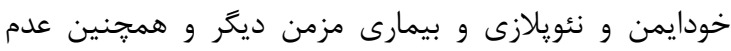

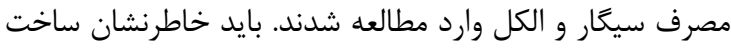

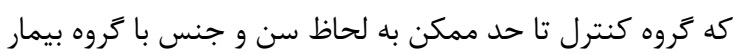
مطابقت داده شد.

خونكيرى و جد/سازى سلول ماى خون محيطى

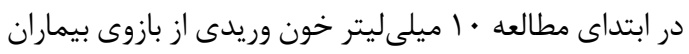

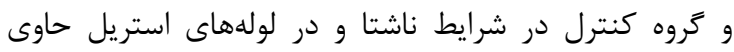
(Ethylenediaminetetraacetic Acid) EDTA براى جداسازى سلولهاى تكهستهاى خون محيطى از يروتكل

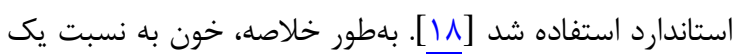

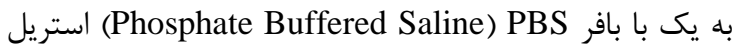
مخلوط گرديد و سيس به نسبت سه به به يك به فايكول استريل

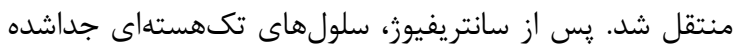
در محيط كشت استاندارد سلولى حاوى Biosera Biosera

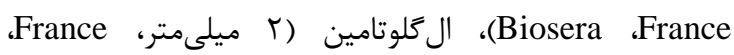
(Biosera

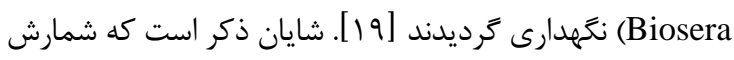

\begin{tabular}{|c|c|c|c|}
\hline سطح معنادارى & تروه بيمار & تروه كنترل & \\
\hline NS & أ & كا به 1 ا & جنسيت (زن به مرد) \\
\hline NS & $Y \wedge / / \Delta \pm N / \Delta T$ & $F \Delta / F T \pm q / V T$ & 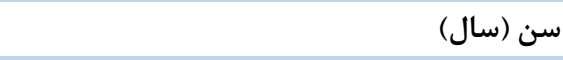 \\
\hline NS & $\vee \varphi / r \varphi \pm \varepsilon / \wedge \Delta$ & $V \cdot \pm 9 / V$ & وزن (كيلوگرم) \\
\hline NS & $1 / 9 \wedge \pm \cdot / 4$ & $I / V T \pm \cdot / 1$ & قد (متر ) \\
\hline NS & $Y Y / \Lambda I \pm Y / \Lambda$ & $r T / T \pm T / D$ & BMI \\
\hline$\leq \cdot 1 \cdot \cdot 1$ & $|Q F / D F \pm \Delta F / V|$ & $\Lambda T / T \Delta \pm V / I T$ & قند ناشتاى پِلاسما (ميلى \\
\hline$\leq \cdot / \cdot \cdot 1$ & $r r V / r \Delta \pm q \Lambda / \Delta$ & $1 \cdot 1 / \Delta F \pm 1 \Delta / 9 \Delta$ & قند بعد از غذاى پيلاسما (ميلى \\
\hline$\leq \cdot 1 \cdot \cdot 1$ & $V / \mathbb{F} \pm \cdot / V V$ & $F / V \pm \cdot / \Delta \Lambda$ & HbA1c \\
\hline NS & $|1 / \Delta F \pm \varepsilon / T|$ & $q / \Gamma \varphi \pm \Delta / r$ & آلبومينورى (ميلى \\
\hline NS & $1 / \cdot r \pm \cdot / 1 Q$ & $\cdot 191 \pm \cdot / 1$ & كراتينين سرم (ميلى \\
\hline NS & $V Y / 9 V \pm \Lambda / \cdot 1$ & $V Q / G Y \pm I I$ & GFR (ميلىليتر در دقيقه بر آI/ متر مربع) \\
\hline NS & $F / Q \cdot \pm r / 19$ & - & طول دوره بيمارى (سال) \\
\hline
\end{tabular}
سلولهاى زنده توسط ترييان بلو در زير ميكروسكوبٍ انجام شد.

جدول ا: ويزَّى هاى جمعيتشناسى و بالينى بيماران و افراد سالم مورد مطالعه

BMI: Body Mass Index; HbA1C: Hemoglobin A1C; GFR: Glomerular filtration rate; NS: Not Significant 


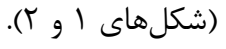

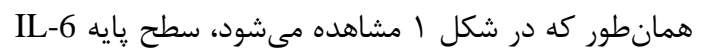

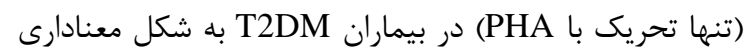

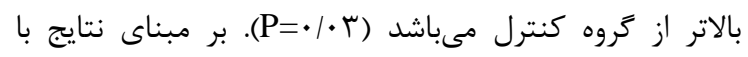

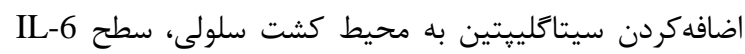

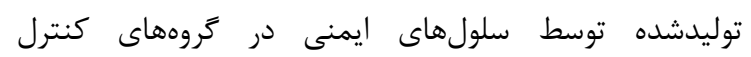

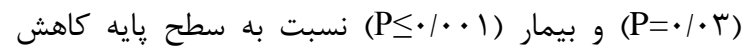

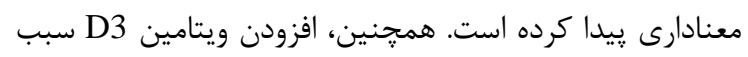

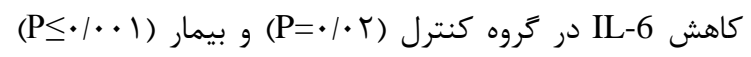
نسبت به سطح پايه شده است. افزودن همزمان ويتامين D3 به له

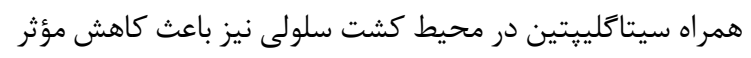

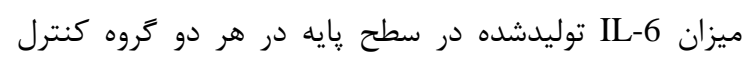

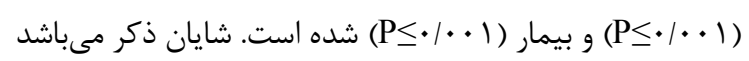

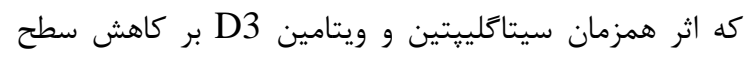

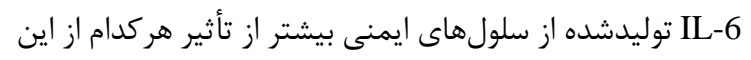

سرم، آلبومينورى، Glomerular Filtration Rate) GFR)، قد و وزن تفاوت معنادارى نداشتهاند. ميزان قند خون ناشتا، قند بعد التومينو

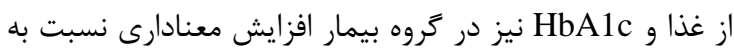

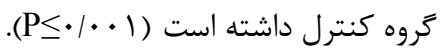

اثر سيتاحلييتين و ويتامين D3 بر توليد 6-IL و م-TNF

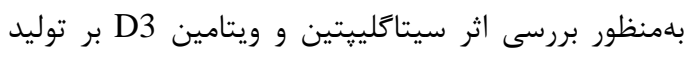

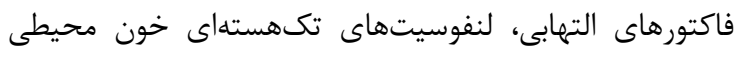

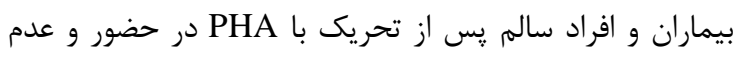

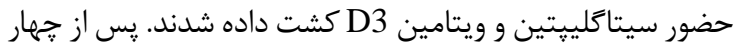
روز مايع رويى حاصل از كشت سلولى جمعآورى كرديد و ميزان

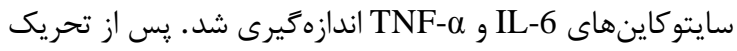
با PHA، سطح IL-6 و TNF-

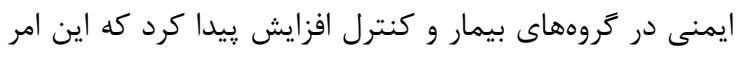

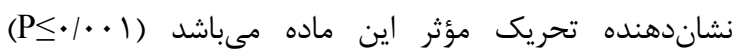

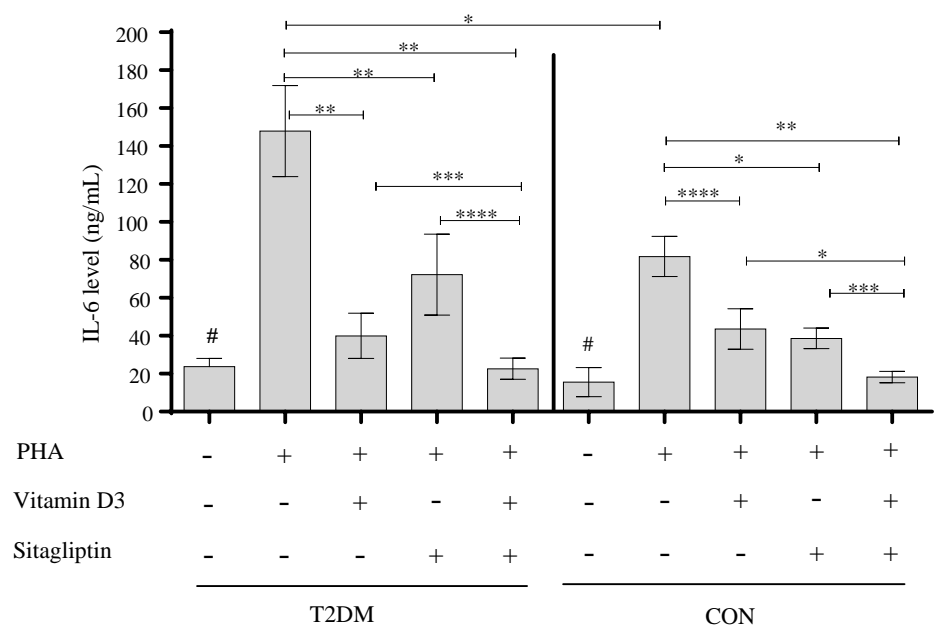

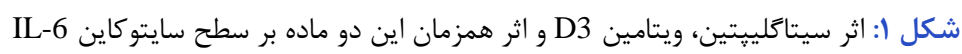

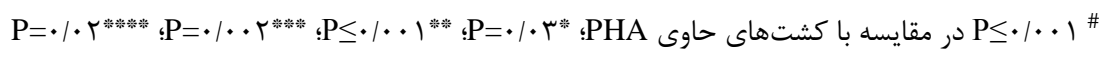

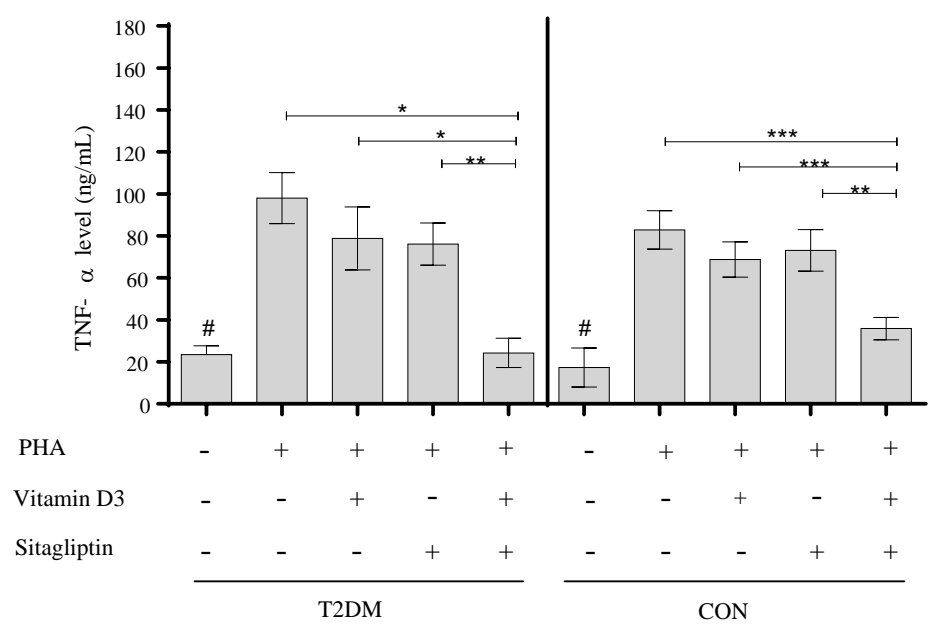

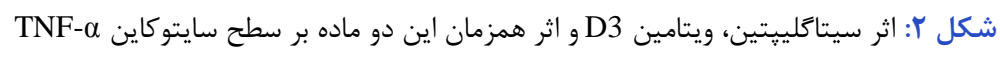

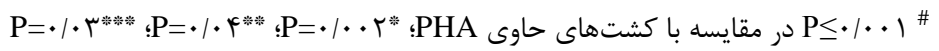


ياتوزنز و ييشبرد بيمارى T2DM نشان داده شده است [مه]. در مطالعه حاضر سطح IL-6 بهعنوان يك ماركر التهابى در كروه

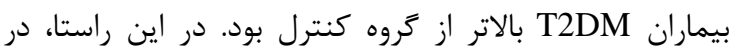

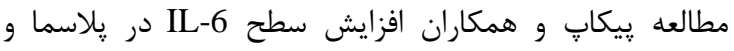
همجنين سويرناتانت كشت سلولى بيماران T2DM در تحريك باد (Lipopolysaccharides) LPS نسبت به كروه كنترل نشان النان

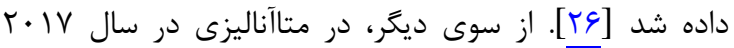

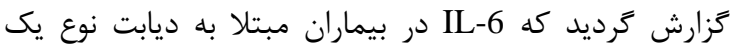

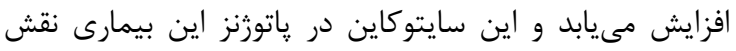

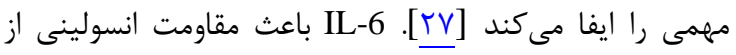

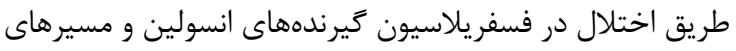

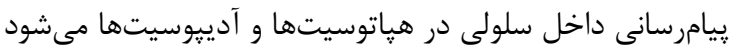

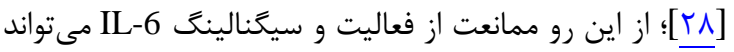
در جلوكيرى از بيمارى هاى التهابى بهويزه T2DM و بهببود علائم

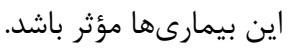

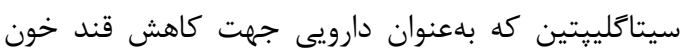

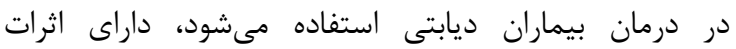

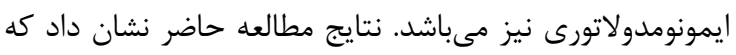

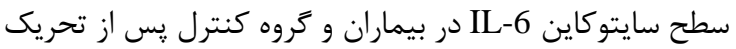

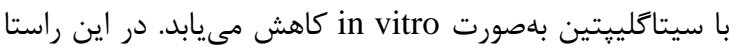
در مطالعهاى كه توسط ويجنسكى و همكاران انجام شد، سطح

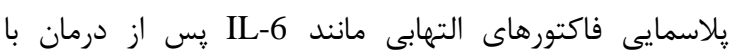

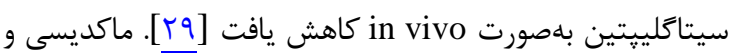

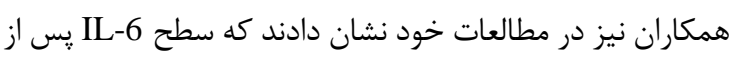

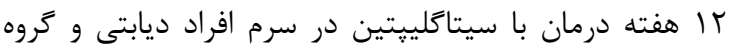

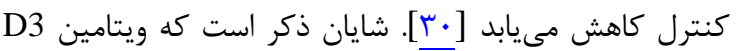

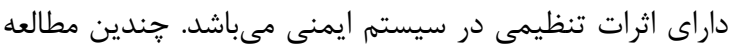

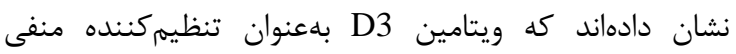

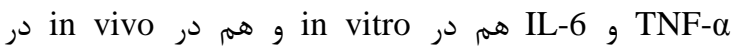
بيمارىهاى خودايمن مانند مالتييل اسكلروزيس و و بيمارى التهابى روده عمل مى كند. در اين مطالعه مشاهده شد كه ويتامين

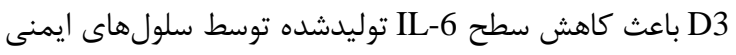

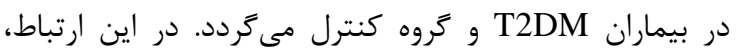

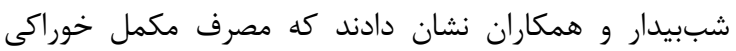

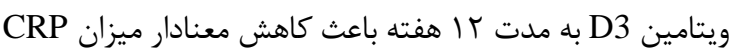

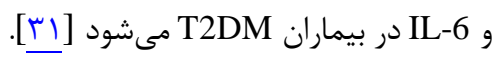
TNF- $\alpha$ مقاومت انسولينى نقش دارد. اين سايتوكاين با اختلال در بيان

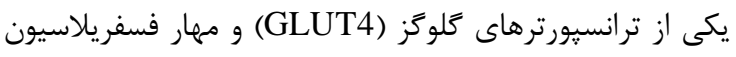

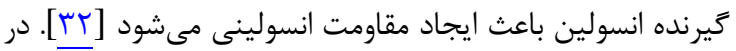

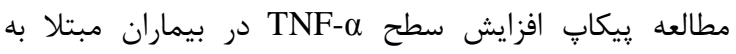

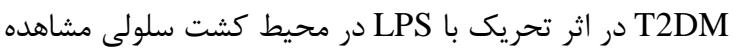

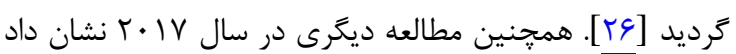
كه سطح سرمى TNF-
مواد به تنهايى است.

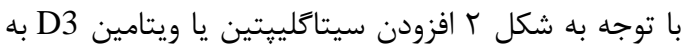
محيط كشت سلولى تفاوت معنادارى را در سطح

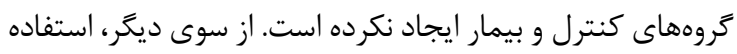

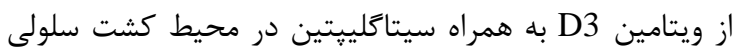

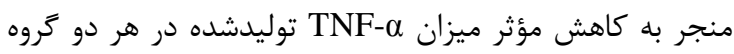

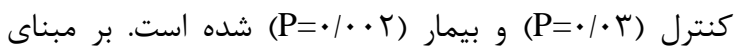

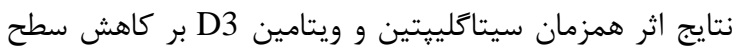
TNF- $\alpha$

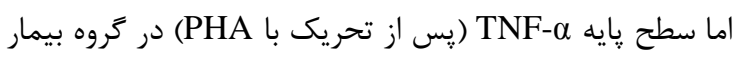
و كروه كنترل تفاوت معنادارى را نشان نمىدهد.

ديابت نوع دو يك بيمارى التهابى مزمن است كه ياتوزنز آن

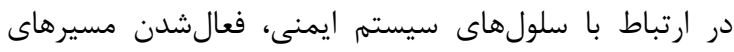

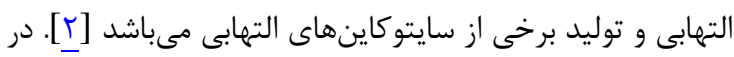

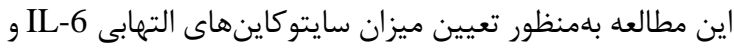
TNF- $\alpha$

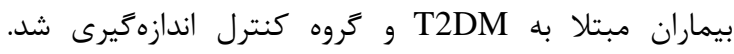

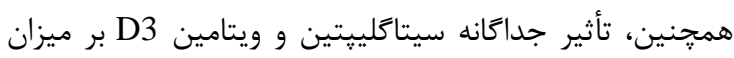

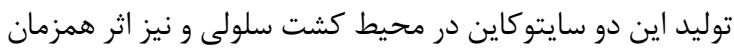

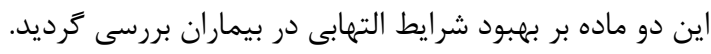

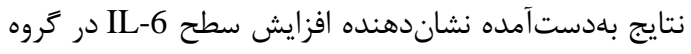

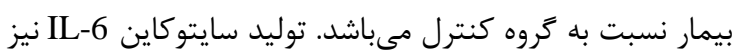

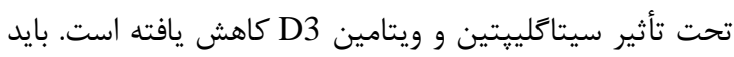

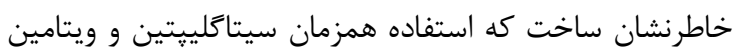
D3 بر كاهش مضاعف سطح اين سايتوكاين مؤثر مىباشند.

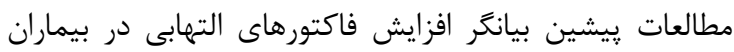

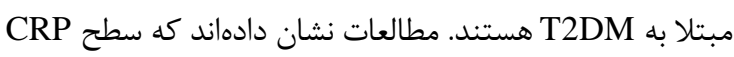

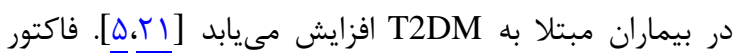

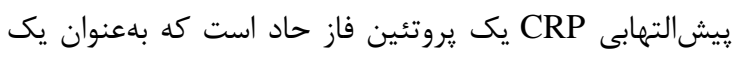

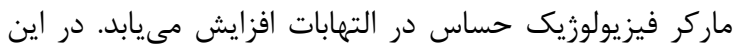

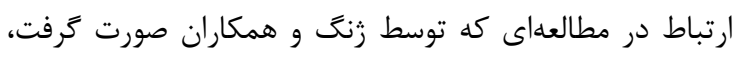

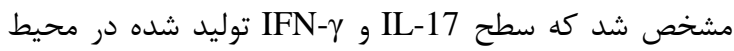

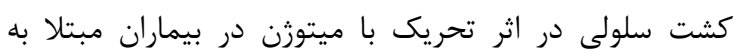

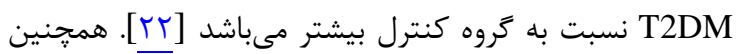

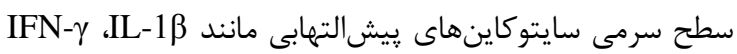

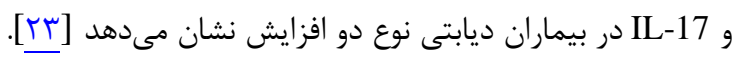

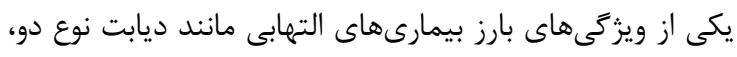

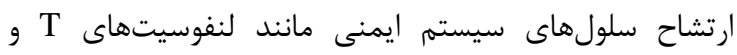

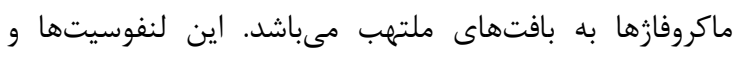
ماكروفازها با توليد مقادير زيادى از سايتوكاينهاى التهائ التهابى مانند إندان

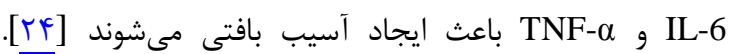

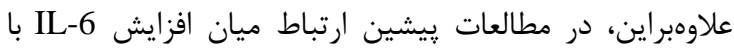


يكى از محدوديتهاى مطالعه حاضر استفاده از دوزهاى

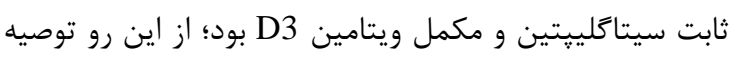

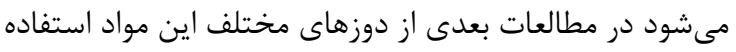

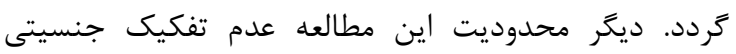

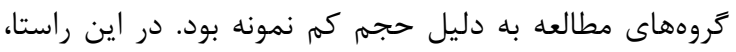

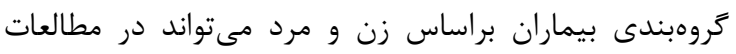

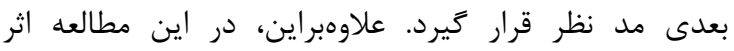

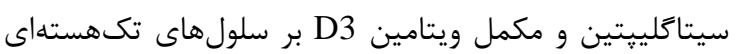

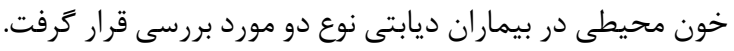

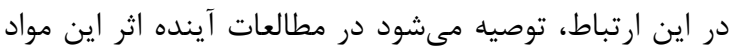

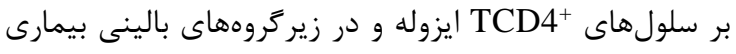

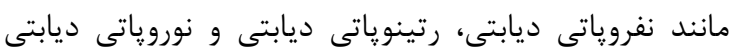
بر مانى كردن.

\section{نتيجه كيرى}

نتايج اين مطالعه نشان داد كه استفاده همزمان از مكمل

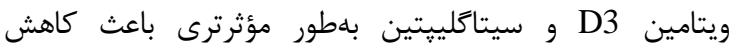

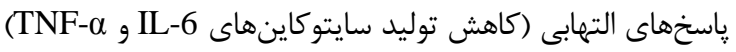

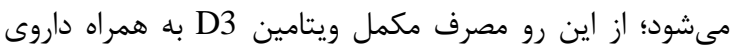

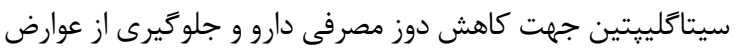
احتمالى آن در درمان بيمارى توصيه مى گردد.

\section{تشكر و قلرواذى}

اين مقاله بركرفته از طرح تحقيقاتى هيأت علمى مصوب

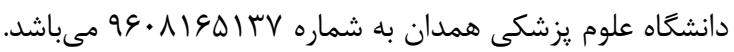
بدينوسيله از معاونت محترم تحقيقات و فناورى دانشخاه علوم

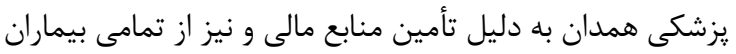

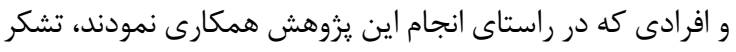

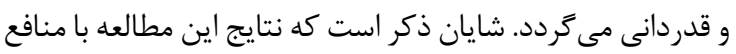

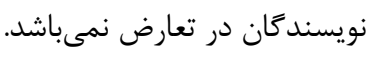

\section{REFERENCES}

1. Olokoba AB, Obateru OA, Olokoba LB. Type 2 diabetes mellitus: a review of current trends. Oman Med J. 2012;27(4):269-73. PMID: 23071876 DOI: 10.5001/omj. $\underline{2012.68}$

2. Sheikh V, Zamani A, Mahabadi-Ashtiyani E, Tarokhian H, Borzouei S, Alahgholi-Hajibehzad M. Decreased regulatory function of $\mathrm{CD} 4(+) \operatorname{CD} 25(+) \operatorname{CD} 45 \mathrm{RA}(+) \mathrm{T}$ cells and impaired IL-2 signalling pathway in patients with type 2 diabetes mellitus. Scand J Immunol. 2018;88(4):e12711. PMID: 30270447 DOI: 10.1111/sji.12711

3. Aso Y, Fukushima M, Sagara M, Jojima T, Iijima T, Suzuki $\mathrm{K}$, et al. Sitagliptin, a DPP-4 inhibitor, alters the subsets of circulating CD4+ T cells in patients with type 2 diabetes. Diabetes Res Clin Pract. 2015;110(3):250-6. PMID: 26508675 DOI: 10.1016/j.diabres.2015.10.012

4. Sromova L, Busek P, Posova H, Potockova J, Skrha P, Andel $\mathrm{M}$, et al. The effect of dipeptidyl peptidase-IV inhibition on circulating $\mathrm{T}$ cell subpopulations in patients with type 2 diabetes mellitus. Diabetes Res Clin Pract. 2016;118:183-92. PMID: 27388675 DOI: 10.1016/j.diabres.2016.06.020

5. Yokota K, Igaki N. Sitagliptin (DPP-4 inhibitor)-induced rheumatoid arthritis in type 2 diabetes mellitus: a case report.
كروه كنترل افزايش مىيابد [19]. در اين مطالعه تغيير معنادارى

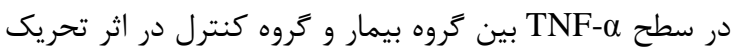

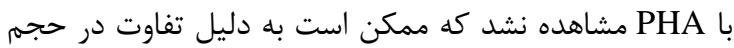

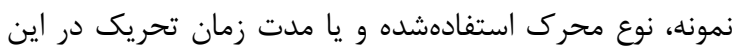

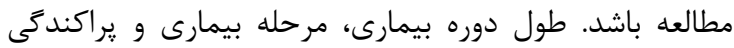
جنسيت نيز مىتوانند در نتايج دخيل باشند. در اين مطالعه دورها

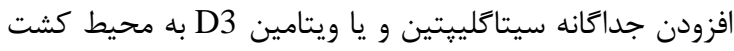
سلولى تفاوت معنادارى رادر سطح

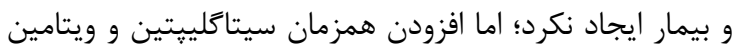

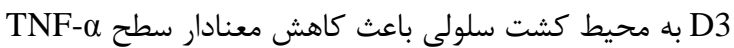
در گروههاى كنترل و بيمار شد. از سوى ديخر، در مطالعه آساهارا

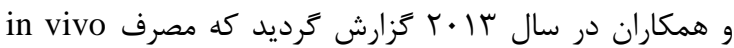
سيتاكلييتين به مدت سه ماه، سطح پيلاسمايى

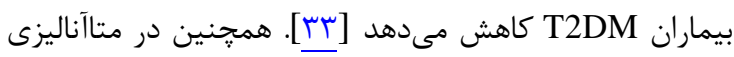

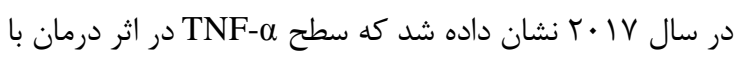

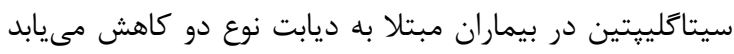

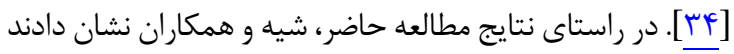
كه مصرف ويتامين D3 به مدت شش ماه تغييرى در سطح TNF- $\alpha$

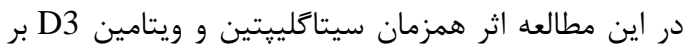

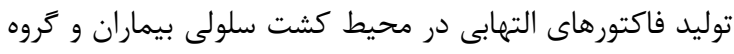

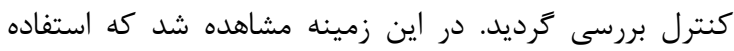
همزمان سيتاحلييتين و ويتامين D3 باعث كاهش توليد و IL-6 از سلولهاى ايمنى در محيط كشت سلولى مئى شودي

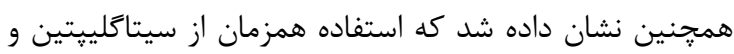

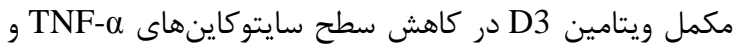

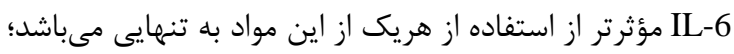

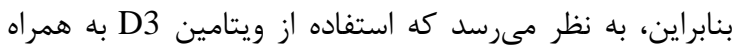

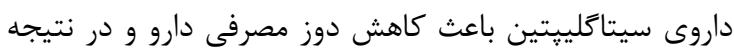

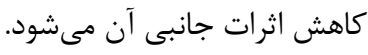

Intern Med. 2012;51(15):2041-4. PMID: 22864134

6. Tremblay AJ, Lamarche B, Deacon CF, Weisnagel SJ, Couture P. Effects of sitagliptin therapy on markers of lowgrade inflammation and cell adhesion molecules in patients with type 2 diabetes. Metabolism. 2014;63(9):1141-8. PMID: 25034387 DOI: 10.1016/j.metabol.2014.06.004

7. Pinheiro MM, Stoppa CL, Valduga CJ, Okuyama CE, Gorjao R, Pereira RM, et al. Sitagliptin inhibit human lymphocytes proliferation and Th1/Th17 differentiation in vitro. Eur J Pharm Sci. 2017;100:17-24. PMID: 28065853 DOI: 10.1016/j.ejps.2016.12.040

8. Sheikh V, Kasapoglu P, Zamani A, Basiri Z, TahamoliRoudsari A, Alahgholi-Hajibehzad M. Vitamin D3 inhibits the proliferation of T helper cells, downregulate CD4(+) T cell cytokines and upregulate inhibitory markers. Hum Immunol. 2018;79(6):439-45. PMID: 29522785 DOI: 10.1016/j.humimm.2018.03.001

9. Borissova AM, Tankova T, Kirilov G, Dakovska L, Kovacheva R. The effect of vitamin D3 on insulin secretion and peripheral insulin sensitivity in type 2 diabetic patients. Int J Clin Pract. 2003;57(4):258-61. PMID: 12800453

10. Alahgholi-Hajibehzad M, Kasapoglu P, Jafari R, Rezaei N. 
The role of $\mathrm{T}$ regulatory cells in immunopathogenesis of myasthenia gravis: implications for therapeutics. Expert Rev Clin Iimmunol. 2015;11(7):859-70. PMID: 25973691 DOI: 10.1586/1744666X.2015.1047345

11. Aivo J, Hanninen A, Ilonen J, Soilu-Hanninen M. Vitamin D3 administration to MS patients leads to increased serum levels of latency activated peptide (LAP) of TGF-beta. $J$ Neuroimmunol. 2015;280:12-5. PMID: 25773149 DOI: 10.1016/j.jneuroim.2015.01.005

12. Terrier B, Derian N, Schoindre Y, Chaara W, Geri G, Zahr $\mathrm{N}$, et al. Restoration of regulatory and effector $\mathrm{T}$ cell balance and B cell homeostasis in systemic lupus erythematosus patients through vitamin D supplementation. Arthritis Res Ther. 2012;14(5):R221. PMID: 23075451 DOI: 10.1186/ar4060

13. Navarro-Gonzalez JF, Mora-Fernandez C. The role of inflammatory cytokines in diabetic nephropathy. $J \mathrm{Am}$ Soc Nephrol. 2008;19(3):433-42. PMID: 18256353 DOI: 10.1681/ASN.2007091048

14. Fruhbeck G, Gomez-Ambrosi J, Muruzabal FJ, Burrell MA. The adipocyte: a model for integration of endocrine and metabolic signaling in energy metabolism regulation. $A m J$ Physiol Endocrinol Metab. 2001;280(6):E827-47. PMID: 11350765 DOI: $10.1152 / a j p e n d o .2001 .280 .6$.E827

15. Kimura A, Kishimoto T. IL-6: regulator of Treg/Th17 balance. Eur J Immunol. 2010;40(7):1830-5. PMID: 20583029 DOI: 10.1002/eji.201040391

16. Qiao YC, Chen YL, Pan YH, Tian F, Xu Y, Zhang XX, et al. The change of serum tumor necrosis factor alpha in patients with type 1 diabetes mellitus: a systematic review and metaanalysis. PloS One. 2017;12(4):e0176157. PMID: 28426801 DOI: 10.1371/journal.pone.0176157

17. Kristiansen OP, Mandrup-Poulsen T. Interleukin-6 and diabetes: the good, the bad, or the indifferent? Diabetes. 2005;54(Suppl 2):S114-24. PMID: 16306329

18. Alahgholi-Hajibehzad M, Durmus H, Aysal F, GulsenParman Y, Oflazer P, Deymeer F, et al. The effect of interleukin (IL)-21 and CD4(+) CD25(++) $\mathrm{T}$ cells on cytokine production of $\mathrm{CD} 4(+)$ responder Tcells in patients with myasthenia gravis. Clin Exp Immunol. 2017;190(2):2017. PMID: 28671717 DOI: 10.1111/cei.13006

19. Zamani A, Salehi I, Alahgholi-Hajibehzad M. Moderate exercise enhances the production of interferon-gamma and interleukin-12 in peripheral blood mononuclear cells. Immune Netw. 2017;17(3):186-91. PMID: 28680380 DOI: 10.4110/in.2017.17.3.186

20. Mahdavinejad L, Alahgholi-Hajibehzad M, Eftekharian MM, Zaerieghane Z, Salehi I, Hajilooi M, et al. Extremely low frequency electromagnetic fields decrease serum levels of interleukin-17, transforming growth factor-beta and downregulate foxp3 expression in the spleen. $J$ Interferon Cytokine Res. 2018;38(10):457-62. PMID: 30328796 DOI: 10.1089/jir.2018.0048

21. Belfki H, Ben Ali S, Bougatef S, Ben Ahmed D, Haddad N, Jmal A, et al. Association between C-reactive protein and type 2 diabetes in a Tunisian population. Inflammation. 2012;35(2):684-9. PMID: 21769439 DOI: 10.1007/s10753011-9361-1

22. Zeng C, Shi X, Zhang B, Liu H, Zhang L, Ding W, et al. The imbalance of Th17/Th1/Tregs in patients with type 2 diabetes: relationship with metabolic factors and complications. J Mol Med (Berl). 2012;90(2):175-86. PMID: 21964948 DOI: 10.1007/s00109-011-0816-5

23. Qiao YC, Shen J, He L, Hong XZ, Tian F, Pan YH, et al.
Changes of regulatory $\mathrm{t}$ cells and of proinflammatory and immunosuppressive cytokines in patients with type 2 diabetes mellitus: a systematic review and meta-analysis. $J$ Diabetes Res. 2016;2016:3694957. PMID: 27777959 DOI: 10.1155/2016/3694957

24. Kim JH, Bachmann RA, Chen J. Interleukin-6 and insulin resistance. Vitam Horm. 2009;80:613-33. PMID: 19251052 DOI: 10.1016/S0083-6729(08)00621-3

25. Wang X, Bao W, Liu J, Ouyang YY, Wang D, Rong S, et al. Inflammatory markers and risk of type 2 diabetes: a systematic review and meta-analysis. Diabetes Care. 2013;36(1):166-75. PMID: 23264288 DOI: $10.2337 / \mathrm{dc} 12-$ 0702

26. Pickup JC, Chusney GD, Thomas SM, Burt D. Plasma interleukin-6, tumour necrosis factor alpha and blood cytokine production in type 2 diabetes. Life Sci. 2000;67(3):291-300. PMID: 10983873

27. Chen YL, Qiao YC, Pan YH, Xu Y, Huang YC, Wang YH, et al. Correlation between serum interleukin-6 level and type 1 diabetes mellitus: a systematic review and meta-analysis. Cytokine. 2017;94:14-20. PMID: 28283222 DOI: 10.1016/ j.cyto.2017.01.002

28. Rehman K, Akash MS, Liaqat A, Kamal S, Qadir MI, Rasul A. Role of interleukin-6 in development of insulin resistance and type 2 diabetes mellitus. Crit Rev Eukaryot Gene Expr. 2017;27(3):229-36. PMID: 29199608 DOI: 10.1615/ CritRevEukaryotGeneExpr.2017019712

29. Wiciński M, Wódkiewicz E, Słupski M, Walczak M, Socha M, Malinowski B, et al. Neuroprotective activity of sitagliptin via reduction of neuroinflammation beyond the incretin effect: focus on alzheimer's disease. Biomed Res Int. 2018;2018:6091014. PMID: 30186862 DOI: 10.1155/2018/ 6091014

30. Makdissi A, Ghanim H, Vora M, Green K, Abuaysheh S, Chaudhuri A, et al. Sitagliptin exerts an antinflammatory action. J Clin Endocrinol Metab. 2012;97(9):3333-41. PMID: 22745245 DOI: 10.1210/jc.2012-1544

31. Shab-Bidar S, Neyestani TR, Djazayery A, Eshraghian MR, Houshiarrad A, Kalayi A, et al. Improvement of vitamin D status resulted in amelioration of biomarkers of systemic inflammation in the subjects with type 2 diabetes. Diabetes Metab Res Rev. 2012;28(5):424-30. PMID: 22344966 DOI: 10.1002/dmrr.2290

32. Akash MSH, Rehman K, Liaqat A. Tumor necrosis factor-alpha: role in development of insulin resistance and pathogenesis of type 2 diabetes mellitus. J Cell Biochem. 2018;119(1):105-10. PMID: 28569437 DOI: 10.1002/jcb.26174

33. Satoh-Asahara N, Sasaki Y, Wada H, Tochiya M, Iguchi A, Nakagawachi R, et al. A dipeptidyl peptidase-4 inhibitor, sitagliptin, exerts anti-inflammatory effects in type 2 diabetic patients. Metabolism. 2013;62(3):347-51. PMID: 23062489 DOI: $10.1016 / \mathrm{j}$. metabol.2012.09.004

34. Atkin SL, Katsiki N, Banach M, Mikhailidis DP, Pirro M, Sahebkar A. Effect of dipeptidyl peptidase-4 inhibitors on circulating tumor necrosis factor-alpha concentrations: a systematic review and meta-analysis of controlled trials. $J$ Diabetes Complications. 2017;31(9):1458-64. PMID: 28647512 DOI: 10.1016/j.jdiacomp.2017.05.016

35. Shih EM, Mittelman S, Pitukcheewanont P, Azen CG, Monzavi R. Effects of vitamin D repletion on glycemic control and inflammatory cytokines in adolescents with type 1 diabetes. Pediatr Diabetes. 2016;17(1):36-43. PMID: 25524404 DOI: 10.1111/pedi.12238 